\title{
Bioaccumulation of microcystins (MCs) in four fish species from Lake Taihu, China: Assessment of risks to humans
}

\author{
Junmei Jia a,b,c, Wei Luo ${ }^{\mathrm{a}, *}$, Yonglong Lu ${ }^{\mathrm{a}}$, John P. Giesy d,e,f \\ a State Key Lab of Urban and Regional Ecology, Research Center for Eco-Environmental Sciences, Chinese Academy of Sciences, Beijing 100085, China \\ b State Key Lab of Environmental Aquatic Chemistry, Research Center for Eco-Environmental Sciences, Chinese Academy of Sciences, Beijing 100085, China \\ c University of Chinese Academy of Science, Beijing 100049, China \\ d Toxicology Center, University of Saskatchewan, Canada \\ e Department of Veterinary Biomedical Sciences, University of Saskatchewan, Canada \\ ${ }^{\mathrm{f}}$ Department of Zoology, National Food Safety and Toxicology Center and Center for Integrative Toxicology, Michigan State University, East Lansing, MI 48824, USA
}

\section{H I G H L I G H T S}

- Concentrations of microcystins are reported for four fishes from Tai Lake, China.

- Accumulation of microcystins among organs, species and feeding guilds was evaluated.

- Consumption of fishes from Tai Lake might pose health risk to local people.

\section{A R T I C L E I N F O}

\section{Article history:}

Received 16 October 2013

Received in revised form 6 April 2014

Accepted 8 April 2014

Available online 3 May 2014

Editor: Kevin V. Thomas

\section{Keywords:}

Accumulation

Hazard

Eutrophication

Asia

Hazardous algal bloom

Cyanotoxins

\begin{abstract}
A B S T R A C T
Microcystins (MCs) are the toxic products of harmful algal blooms and they accumulate in fish. The accumulation of MCs in fish living in different trophic levels from different parts of Lake Taihu was determined. This information was then used to evaluate the risks posed by the MCs in fish to human health. The concentrations of three MCs, MC-LR, MC-YR and MC-RR, were quantified in the following four fish species: silver carp (Hypophthalmichthys molitrix), bighead carp (Aristichthys nobilis), crucian carp (Carassius auratus) and common carp (Cyprinus carpio), using high performance liquid chromatography interfaced with tandem (triple quadrupole) mass spectrometry. The mean concentrations of MCs in the muscle, the kidney, the intestinal wall and the heart were significantly different among the four fishes except in the liver. C. carpio contained the highest mean concentration of MCs in the muscle $(31.7 \pm 12.1 \mathrm{ng} / \mathrm{g}$, dry mass $(\mathrm{dm}))$, whereas $C$. auratus had the highest mean concentrations of MCs in the liver $(45.4 \pm 44.5 \mathrm{ng} / \mathrm{g}, \mathrm{dm})$, kidney $(114 \pm 51.1 \mathrm{ng} / \mathrm{g}, \mathrm{dm})$, intestinal wall $\left(2.04 \times 10^{3} \pm 4.43 \times\right.$ $\left.10^{3} \mathrm{ng} / \mathrm{g}, \mathrm{dm}\right)$ and heart $(59.5 \pm 26.7 \mathrm{ng} / \mathrm{g}, \mathrm{dm})$. The mean concentration of MCs in the intestinal walls of the fish species was significantly higher than in other organs $(p<0.01)$. The fish from Meiliang Bay had significantly higher concentrations of MCs than those from the centre, west or south banks of the lake $(p<0.01)$. The body lengths and masses of the fish were negatively correlated with the concentrations of MCs in the kidney $(p<0.05)$ and heart $(p<0.01)$. The average daily intake (ADI) of MCs in the muscle of all fishes exceeded the provisional tolerable daily intake (TDI) set by World Health Organization. The estimated daily intakes of MCs in $55.6 \%$ of the muscle samples exceeded the TDI. The MCs in the tissues of the fish from Lake Taihu pose potential risks to the health of humans who consume these four fish species.
\end{abstract}

(C) 2014 Elsevier B.V. All rights reserved.

\section{Introduction}

Microcystins (MCs) are a group of cyclic peptides produced by several genera of cyanobacteria, formerly blue green algae (McElhiney and Lawton, 2005), which are potent cyanotoxins (Chorus and Bartram, 1999). MCs are potent hepatotoxins (Carmichael, 1992; Dawson,

\footnotetext{
* Corresponding author. Tel./fax: + 861062849466.

E-mail address: luow@rcees.ac.cn (W. Luo).
}

1998) and promoters of tumour growth (Nishiwakimatsushima et al., 1992). They inhibit eukaryotic protein phosphatase types 1 and $2 \mathrm{~A}$ resulting in the excessive phosphorylation of cytoskeletal filaments, which ultimately leads to liver failure, and MCs have also been implicated in the deaths of birds, wild animals, livestock and fish (Carmichael, 1994; Kaebernick and Neilan, 2001). Furthermore, MCs have been detected in the blood serum of anglers because of their long-term exposure to MCs through drinking water and the consumption of aquatic products (Chen et al., 2009). 
In the natural environment, MCs accumulate in a wide range of aquatic animals, including fish (Magalhães et al., 2003; Mohamed et al., 2003), shrimps (Chen and Xie, 2005b), gastropods (Chen and Xie, 2005b; Zhang et al., 2012; Zurawell et al., 1999) and bivalves (Chen and Xie, 2005a; Williams et al., 1997). MCs are found in both the viscera and also in the edible muscle/foot. Although there have been extensive studies on the bioaccumulation of MCs in fish under laboratory conditions (Kotak et al., 1996; Li et al., 2005; Mohamed and Hussein, 2006; Xie et al., 2004), few studies have investigated the accumulation of MCs in fish under field conditions. Field studies have been conducted in Brazil (Magalhàes et al., 2001), Egypt (Mohamed et al., 2003), Argentina (Ame et al., 2010) and Portugal (Vasconcelos and Pereira, 2001). Currently, studies of MCs in fish have focused on its accumulation in muscle and liver (Cazenave et al., 2005; Magalhães et al., 2003; Magalhaes et al., 2001; Mohamed et al., 2003) because humans eat the muscle, whereas the liver accumulates the highest concentrations of MCs. However, few studies have simultaneously evaluated multiple fish organs, such as the gut, kidney and heart, which may also accumulate MCs and affect the health of aquatic animals. MCs accumulate in the phytoplanktivorous silver carp (Hypophthalmichthys molitrix), herbivorous white bream (Parabramis pekinensis), omnivorous common carp (Cyprinus carpio),crucian carp (Carassius auratus) and carnivorous species, including the predatory carps (Culter ilishaeformisand Culter erythropterus), the yellow catfish (Pseudobagrus fulvidraco), Osbeck's grenadier anchovy (Coilia ectenes) and the salangid icefish (Neosalanx taihuensis); however, it is not currently known which fish species accumulate the highest amounts of MCs in their tissues (Gkelis et al., 2006; Xie et al., 2005; Zhang et al., 2009).

Information on the concentrations of MCs in wild fish in China, where freshwater fish are commonly and extensively consumed regardless of the danger of MCs, is lacking (Xie et al., 2005). Because freshwater fish comprise $40 \%-50 \%$ of the total fish consumption in China, determining the accumulation of MCs in freshwater fish is of great importance for assessing any potential risks to human health. Lake Taihu, located in the Yangtze River Delta, is the third largest freshwater lake in China and is an important fishery that is surrounded by developed areas of the river delta. The mean annual harvest of fish from Lake Taihu was $1.13 \times 10^{4}, 1.41 \times 10^{4}$ and $1.79 \times 10^{4}$ metric tons $(\mathrm{mt})$ during the 1970s, 1980s and 1990s, respectively (Chen and Zhu, 2008). In 2008, the harvest reached $2.93 \times 10^{4}$ MT. However, since the $1980 \mathrm{~s}$, Lake Taihu has experienced a steady increase in eutrophication with annual occurrences of surface blooms containing cyanobacteria (Pu et al., 1998; Zhang et al., 2009), which can affect fish, particularly those at the top of the food web (Xie et al., 2005). It has been reported that during the past few decades, the fish community composition, trophic dynamics and fish biomass production in Lake Taihu have decreased (Chen and Zhu, 2008). In the past, greater attention was paid to water quality (Otten et al., 2012), eutrophication (Chen and Mynett, 2003) and algal blooms (Pan et al., 2011), than to the bioaccumulation of MCs in aquatic animals in Lake Taihu. Several studies on the accumulation of MCs in Lake Taihu fish have been conducted since the mid-1980s when blooms of Microcystis sp. first occurred (Chen et al., 2006; Qiu et al., 2007b; Zhang et al., 2009). However, those studies were limited to the northern region of the lake, where Microcystis sp. contamination was most severe. Therefore, these studies were insufficient for assessing the risks posed by human consumption of fish from the lake. Furthermore, a comprehensive investigation of the MC concentrations in various organs of various freshwater fish from various locations across the lake has never been conducted, despite its practical importance for public health protection in this densely populated region where people rely heavily on Lake Taihu fish for dietary protein.

This study was performed in 2011, and its objectives were as follows: a) examine the accumulation of specific MCs, MC-RR, MC-YR and MC-LR, in fish from various trophic levels and feeding guilds; b) assess the geographic distribution of the concentration of MCs in fish from several areas of Lake Taihu; and c) evaluate the risks of MCs in Lake Taihu fish to human health.

\section{Materials and methods}

\subsection{Sampling locations}

Lake Taihu is located at the centre of the Yangtze River delta, in Eastern China $\left(30^{\circ} 56^{\prime}-31^{\circ} 33^{\prime} \mathrm{N}, 119^{\circ} 55^{\prime}-120^{\circ} 54 \mathrm{E}\right)$. It has a total surface area of approximately $2338 \mathrm{~km}^{2}$, with a mean water depth of $1.9 \mathrm{~m}$ and a maximum depth of approximately $2.6 \mathrm{~m}$ (Zhang et al., 2009). The water in Lake Taihu is as an important source of water for drinking, crop irrigation, aquaculture and industries, and it is popular for recreation and tourism. The watershed of Lake Taihu is one of the most economically developed and rapidly urbanising areas in the world, with five large cities situated around the lake. In addition, over 200 streams flow through adjacent cities into the lake. Since the 1980s, the fluxes of pollutants discharged from agriculture, industries and other human activities into the lake have increased greatly, and the resulting eutrophication of Lake Taihu has accelerated (Jin and Hu, 2003).

Lake Taihu is divided into nine regions (Fig. 1). Four of these regions, including Meiliang Bay (MLB), lake centre (LC), west coast (WC) and south coast (SC), were selected as sampling locations. The MLB and WC regions were selected because they have recently been the most susceptible to Microcystis sp. blooms (Sun et al., 2012), whereas the LC and SC regions together comprise a significant portion (57.2\%) of the lake surface area. Fish account for approximately $77 \%$ of the total aquatic products from Lake Taihu. The most important planktivorous fish are H. molitrix and A. nobilis, whereas C. auratus and C. carpio are important omnivorous fish. These fish are all native to Lake Taihu and economically important for human consumption (Peng et al., 2010; Zhang et al., 2009). The harvest of H. molitrix, A. nobilis, C. auratus and C. carpio comprised nearly $13 \%$ of the total fish harvest. Both H. molitrix and A. nobilis are also exported to other countries and comprise up to $18 \%$ of the total freshwater fish production in the world (Xie et al., 2004; Xie and Liu, 2001). Therefore, all of these fish discussed above are economically important (Peng et al., 2010; Zhang et al., 2009).

\subsection{Sample collection and processing}

A total of 46 fish samples, classified as either phytoplanktivorous, which included $H$. molitrix and $A$. nobilis and the omnivorous species C. auratus and C. carpio, were collected from MLB, WC, SC and LC of Lake Taihu in September, 2011(Table 1). The highest concentrations of MCs in fish usually occur in September following the peak in cyanobacteria blooms. Three individuals of each fish species were collected from each of the four locations, except for H. molitrix at MLB. After the mass and length of each fish were measured, it was immediately dissected and the tissues including the muscle, the liver, the kidney, the intestinal wall and the heart were excised. The tissues were carefully washed separately with distilled water to avoid cross-contamination, and then immediately frozen at $-80{ }^{\circ} \mathrm{C}$ for storage prior to the quantification of MCs. The tissue samples were lyophilised and the MCs were extracted using previously described methods (Xie et al., 2004). Briefly, approximately $0.4 \mathrm{~g}$ dry mass $(\mathrm{dm})$ lyophilised samples were homogenised and extracted three times with water:butanol: methanol $=1: 4: 15$ with stirring. The extract was centrifuged and the supernatant was diluted with water and applied to $0.5 \mathrm{~g}$ reversed phase ODS cartridge preconditioned by washing with methanol $(\mathrm{MeOH})$ and water. The column was first washed with water, followed by water-MeOH. The MCs were eluted from the column with $90 \%$ $\mathrm{MeOH}$ and evaporated to dryness. The dried residue was dissolved in $\mathrm{MeOH}$, applied to a silica gel column and then eluted with $70 \% \mathrm{MeOH}$. The toxin-containing fraction was also evaporated to dryness. 


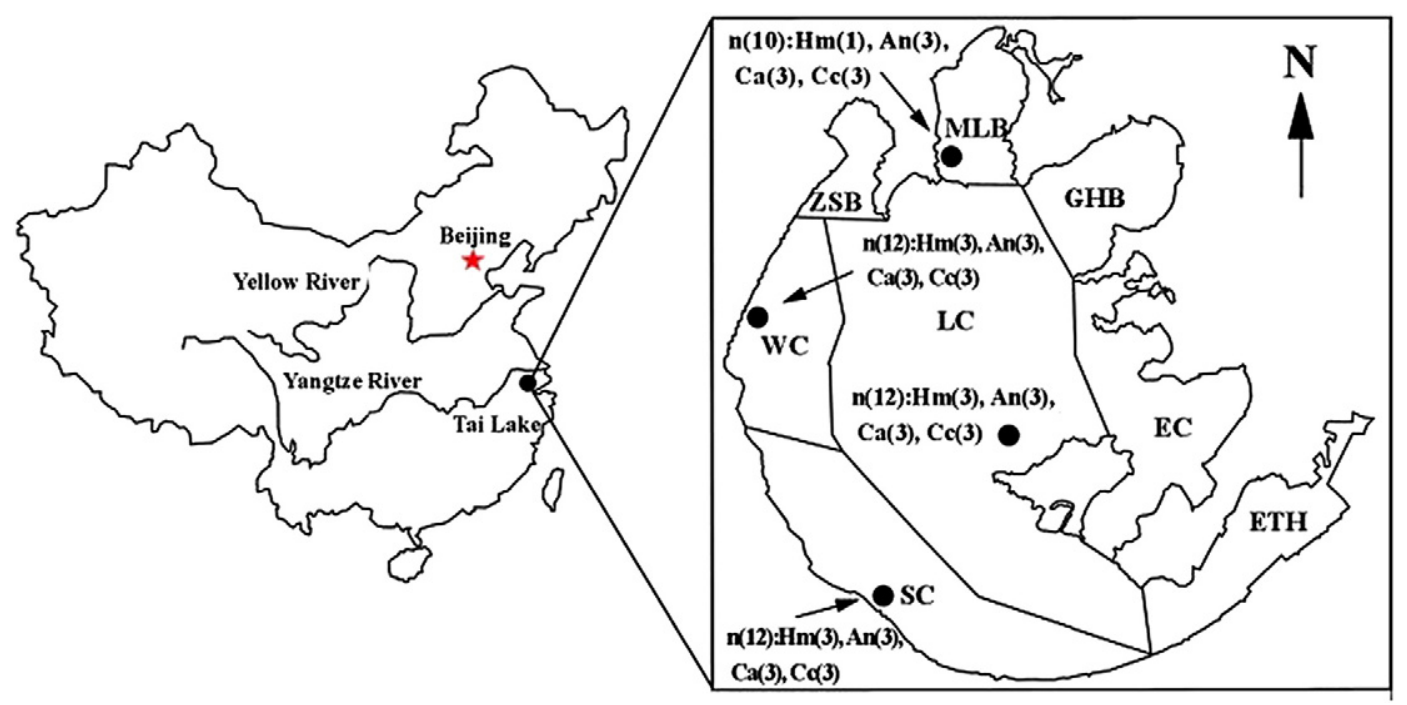

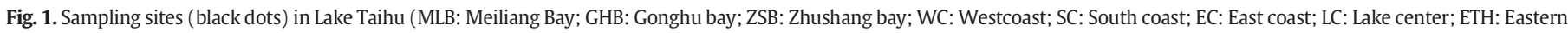
Taihu; n: Sampling size; Hm: Hypophthalmichthys molitrix; An: Aristicbthys nobilis; Ca: Carassius auratus; Cc: Cyprinus carpio).

\subsection{Quantification of microcystins}

MCs were quantified using previously described methods (Li, 2011). Samples in 100\% MeOH were injected into an Agilent 6460 QQQ high performance liquid chromatography (HPLC) (Santa Clara, California, USA) equipped with an ODS column (Cosmosil 5C18-AR, $4.6 \times$ $150 \mathrm{~mm}$, Nacalai, Japan) and interfaced with a triple quadrupole, tandem mass spectrometer (MS/MS). The analytes were separated in the following two phases: phase $\mathrm{A}(\mathrm{MeOH})$ and phase $\mathrm{B}(0.1 \%$ aqueous solution of formic acid (FA)). The flow rate of the mobile phase was $0.5 \mathrm{~mL} \mathrm{~min}^{-1}$, with a gradient profile as follows ( $\mathrm{t}$ in $\mathrm{min}$ ): $\mathrm{t}_{0}=80 \%$; $\mathrm{t}_{3}=65 \% ; \mathrm{t}_{5}=65 \% ; \mathrm{t}_{7}=35 \% ; \mathrm{t}_{8}=35 \% ; \mathrm{t}_{8.5}=80 \%$; and $\mathrm{t}_{12}=80 \%$. The column oven temperature was set at $40{ }^{\circ} \mathrm{C}$.

The effluent from the column was introduced directly into a triple quadrupole, tandem mass detector operated in positive ESI mode. Nitrogen was used as both the drying and sheath gas and collision gas. The ESI source parameters were as follows: gas temperature $350{ }^{\circ} \mathrm{C}$; gas flow $11 \mathrm{~L} / \mathrm{min}$; nebuliser gas pressure $50 \mathrm{psi}$; and capillary voltage 5 $\mathrm{kV}$. The fragmentation voltage and collision energy were selected for each compound individually and ranged from 100 to $250 \mathrm{~V}$ and 20 to $100 \mathrm{eV}$, respectively. The samples were analysed by fast chromatography-MS/MS in multiple reaction monitoring (MRM) mode with delta EMV (+) 400. The instrument control, data processing and analysis were performed with the Masshunter software. The MC concentrations were determined by comparing the peak areas of the test samples with those of the standards available (MC-LR, MC-RR and MC-YR, AXXORA EUROPE-Switzerland).

\subsection{Recovery experiments}

The recovery experiments were conducted in sextuplet by spiking $400 \mathrm{mg}$ lyophilised fish samples (liver) with a solution that contained a mixture of $1 \mu \mathrm{g} / \mathrm{g}$ each of MC-RR, MC-YR and MC-LR. The recovery and relative standard deviation of the analytical method were then calculated. The mean recoveries for the fish liver $(n=6)$ were $48.2 \%$ (relative standard deviations ( $\mathrm{RSD}=9.6 \%), 93.3 \%(\mathrm{RSD}=0.2 \%)$ and $86.2 \%(\mathrm{RSD}=0.5 \%$ ) for MC-RR, MC-YR and MC-LR, respectively).

\subsection{Statistical analysis}

The frequency distributions of the MC concentrations approximated a normal distribution. Analysis of variance (ANOVA) was used to determine whether the MC concentrations varied significantly based on the species, location and organ. Pearson product moment correlations were used to assess the associations between biological parameters, such as wet mass and fish length, and the concentrations of MCs in the various organs. The criteria for significance were set at $p<0.01$ and $p<0.05$. Regression analysis was used to determine the relationship between the MC concentrations in the different fish organs and its body length and wet mass. All data were processed statistically using SPSS 17.0.

\section{Results}

\subsection{MCs in different organs of the phytoplanktivorous fish species}

The concentrations of MC-RR, MC-YR, MC-LR and MCs in H. molitrix and $A$. nobilis varied among the organs and locations (Table 2). For $H$. molitrix, the heart had concentrations of MC-RR that accounted for $100 \%$ of the total MCs (100\%), followed by the intestinal wall (76\%), muscle (70\%), kidney (67\%) and liver (58\%). By contrast, the largest percentages of MC-YR and MC-LR occurred in the muscle and liver, respectively. The MC concentrations were significantly higher in the intestinal wall than the muscle, the liver, the kidney or the heart $(p<0.05)$,

Table 1

Biological characteristics of the four fishes studied.

\begin{tabular}{|c|c|c|c|c|c|c|}
\hline Species & $\begin{array}{l}\text { Common } \\
\text { name }\end{array}$ & $\mathrm{n}$ & $\begin{array}{l}\text { Length } \pm \mathrm{SD} \\
(\mathrm{cm})\end{array}$ & $\begin{array}{l}\text { Wet weight } \pm \text { SD } \\
(\mathrm{g})\end{array}$ & Feeding type and diet & Reference \\
\hline Hypophthalmichthys molitrix & Silver carp & 10 & $44.1 \pm 6.1$ & $1.07 \times 10^{3} \pm 404$ & Planktivorous; algae and zooplankton & Xie et al. (2005) \\
\hline Aristicbthys nobilis & Bighead carp & 12 & $42.8 \pm 2.6$ & $1.05 \times 10^{3} \pm 210$ & $\begin{array}{l}\text { Planktivorous; blue green algae, zooplankton, } \\
\text { and aquatic insects and larva }\end{array}$ & \\
\hline Carassius auratus & Crucian carp & 12 & $21.8 \pm 3.4$ & $187 \pm 90$ & $\begin{array}{l}\text { Omnivorous; attached algae, detritus, } \\
\text { benthic diatoms, and filamentous algae }\end{array}$ & Xie et al. (2005) \\
\hline Cyprinus carpio & Common carp & 12 & $36.6 \pm 5.4$ & $748 \pm 331$ & Omnivorous; detritus and benthic invertebrates & Melwani et al. (2009); Xie et al. (2005) \\
\hline
\end{tabular}


Table 2

Concentration of MCs (MC-RR, MC-YR and MC-LR) in various organs of four fishes.

\begin{tabular}{|c|c|c|c|c|c|c|c|}
\hline Fish & Species & $\mathrm{MC}(\mathrm{ng} / \mathrm{g}, \mathrm{dm})$ & Muscle & Liver & Kidney & Intestinal wall & Heart \\
\hline \multirow[t]{12}{*}{ Phytoplanktivorous fish } & \multirow[t]{4}{*}{ Hypophthalmichthys molitrix } & MC-RR & $20.3 \pm 0.766$ & $23.3 \pm 1.51$ & $30.0 \pm 10.1$ & $220 \pm 172$ & $26.3 \pm 22.6$ \\
\hline & & MC-YR & $5.66 \pm 3.93$ & $6.60 \pm 4.01$ & $5.57 \pm 3.35$ & $22.9 \pm 43.6$ & 0 \\
\hline & & MC-LR & $3.17 \pm 0.261$ & $10.1 \pm 6.18$ & $9.52 \pm 2.57$ & $46.0 \pm 107$ & 0 \\
\hline & & MCs & $29.1 \pm 3.95$ & $40.0 \pm 10.1$ & $45.1 \pm 14.4$ & $289 \pm 176$ & $26.3 \pm 22.6$ \\
\hline & \multirow[t]{4}{*}{ Aristicbthys nobilis } & MC-RR & $19.6 \pm 0.51$ & $19.9 \pm 2.05$ & $80.9 \pm 64.0$ & $454 \pm 1.19 \times 10^{3}$ & $15.4 \pm 12.5$ \\
\hline & & MC-YR & $2.72 \pm 2.54$ & $4.76 \pm 2.84$ & $4.77 \pm 1.31$ & $6.26 \pm 4.40$ & 0 \\
\hline & & MC-LR & $3.12 \pm 0.61$ & $5.44 \pm 3.51$ & $6.80 \pm 2.48$ & $10.5 \pm 6.36$ & 0 \\
\hline & & MCs & $25.5 \pm 2.67$ & $30.1 \pm 5.97$ & $93.5 \pm 64.0$ & $471 \pm 1.19 \times 10^{3}$ & $15.4 \pm 12.5$ \\
\hline & \multirow[t]{4}{*}{ Total } & MC-RR & $19.9 \pm 0.701$ & $21.5 \pm 2.51$ & $57.8 \pm 53.5$ & $348 \pm 874$ & $20.4 \pm 18.2$ \\
\hline & & MC-YR & $3.98 \pm 3.46$ & $5.64 \pm 3.49$ & $5.13 \pm 2.43$ & $13.8 \pm 29.9$ & 0 \\
\hline & & MC-LR & $3.14 \pm 0.480$ & $7.66 \pm 5.39$ & $8.04 \pm 2.82$ & $26.6 \pm 72.5$ & 0 \\
\hline & & MCs & $27.1 \pm 3.69$ & $34.8 \pm 9.48$ & $70.9 \pm 53.0$ & $388 \pm 871$ & $20.4 \pm 18.2$ \\
\hline \multirow[t]{12}{*}{ Omnivorous fish } & \multirow[t]{4}{*}{ Carassius auratus } & MC-RR & $20.1 \pm 0.56$ & $27.5 \pm 24.7$ & $77.7 \pm 35.0$ & $1.87 \times 10^{3} \pm 4.32 \times 10^{3}$ & $59.5 \pm 26.7$ \\
\hline & & MC-YR & $3.15 \pm 2.63$ & $7.40 \pm 9.18$ & $14.2 \pm 11.7$ & $12.4 \pm 19.3$ & 0 \\
\hline & & MC-LR & $3.42 \pm 1.67$ & $10.5 \pm 12.5$ & $22.1 \pm 7.53$ & $164 \pm 291$ & 0 \\
\hline & & MCs & $26.7 \pm 3.35$ & $45.4 \pm 44.5$ & $114 \pm 51.1$ & $2.04 \times 10^{3} \pm 4.43 \times 10^{3}$ & $59.5 \pm 26.7$ \\
\hline & \multirow[t]{4}{*}{ Cyprinus carpio } & MC-RR & $20.1 \pm 0.692$ & $19.6 \pm 3.10$ & $21.9 \pm 2.15$ & $24.0 \pm 6.23$ & $19.0 \pm 7.8$ \\
\hline & & MC-YR & $8.40 \pm 12.1$ & $3.83 \pm 1.99$ & $4.68 \pm 1.50$ & $25.2 \pm 59.0$ & 0 \\
\hline & & MC-LR & $3.12 \pm 0.402$ & $6.08 \pm 2.22$ & $5.72 \pm 1.64$ & $84.0 \pm 233$ & 0 \\
\hline & & MCs & $31.7 \pm 12.1$ & $29.5 \pm 5.48$ & $32.3 \pm 2.88$ & $133 \pm 297$ & $19.0 \pm 7.8$ \\
\hline & \multirow[t]{4}{*}{ Total } & MC-RR & $20.1 \pm 0.618$ & $23.5 \pm 17.7$ & $49.8 \pm 37.4$ & $945 \pm 3.13 \times 10^{3}$ & $39.2 \pm 28.2$ \\
\hline & & MC-YR & $5.78 \pm 8.97$ & $5.60 \pm 6.75$ & $9.44 \pm 9.51$ & $18.8 \pm 43.4$ & 0 \\
\hline & & MC-LR & $3.27 \pm 1.20$ & $8.30 \pm 9.07$ & $13.9 \pm 9.90$ & $124 \pm 261$ & 0 \\
\hline & & MCs & $29.2 \pm 9.02$ & $37.5 \pm 32.0$ & $73.1 \pm 53.7$ & $1.09 \times 10^{3} \pm 3.22 \times 10^{3}$ & $39.2 \pm 28.2$ \\
\hline
\end{tabular}

whereas there were no significant differences in the concentrations of MCs in the muscle, liver, kidney and heart $(p>0.05)$.

For A.nobilis, the ratio of MC-RR to the total MCs was in the following order: heart $(100 \%)>$ intestinal wall $(96 \%)>$ kidney $(87 \%)>$ muscle (75\%) > liver (66\%). Conversely, the largest percentages of MC-YR and MC-LR both occurred in the liver. In A. nobilis, the concentrations of MCs were higher in the intestinal wall than in the muscle or heart $(p<0.05)$, although there were no significant differences in the MC concentrations of the other organs ( $p>0.05$ ) (Table 2). In general, both these fish species exhibited similar MC accumulation trends in their tissues. The MC concentrations in the different organs of both species decreased in the following order: intestinal wall $>$ kidney $>$ liver $>$ muscle $>$ heart. However, the MC concentrations in the $H$. molitrix muscle and heart were higher than in the same tissues of $A$. nobilis $(p<0.01)$. No significant differences were observed between the MC concentrations in the other organs of $H$. molitrix and A. nobilis $(p>0.05)$. These results indicate that the accumulation and disposition of MCs among the tissues of these two phytoplanktivorous fishes were similar.

\subsection{MCs in the organs of the omnivorous fish species}

The two omnivorous fish $C$. auratus and $C$. carpio accumulated different amounts of MCs (Table 2). For C. auratus, the concentrations of MC-RR were highest in the heart, which accounted for the largest percentage of the total MCs (100\%), followed by the intestinal wall (91\%), muscle (75\%), kidney (68\%) and liver (61\%). However, the largest percentages of MC-YR and MC-LR both occurred in the liver. For C. auratus, the MC concentrations were significantly higher in the intestinal wall than in the muscle, liver, kidney or heart $(p<0.05)$, whereas there were no significant differences in the MC concentrations in the muscle, liver, kidney and heart ( $p>0.05)$.

or C. carpio, MC-RR as a percentage of total MCs decreased in the following order: heart $(100 \%)>$ kidney $(68 \%)>$ liver $(67 \%)>$ muscle $(63 \%)>$ intestinal wall (18\%). By contrast, MC-YR and MC-LR as a percentage of the total MCs were highest in the muscle and the intestinal wall, respectively. Only the intestinal wall had greater than 50\% MC-LR (63\%). C. carpio had higher concentrations of MCs in the intestinal wall than the heart, but there were no significant $(p>0.05)$ differences in the MC concentrations of the other organs. However, $C$. auratus and C. carpio exhibited differential accumulation of MCs in different organs. The mean MC concentrations in the different $C$. auratus organs was as follows: intestinal wall $>$ kidney $>$ liver $>$ heart $>$ muscle, whereas for $C$. carpio, the order was as follows: intestinal wall $>$ kidney $>$ muscle $>$ liver $>$ heart (Table 2). C. carpio had higher MC concentrations in the muscle than $C$. auratus $(p<0.01)$, whereas the opposite was true for the kidney, the intestinal wall and the heart $(p<0.05, p<0.01$ and $p<0.01$, respectively).

\subsection{Comparison of $M C$ concentrations in phytoplanktivorous and omnivorous fishes}

The concentrations of MC-RR, MC-YR and MC-LR varied among the organs and species of phytoplanktivorous and omnivorous fishes (Table 2). In general, MC-RR comprised $60-100 \%$ of the total MCs in all organs of both species, except for the intestinal wall of $C$. carpio (18\%). MC-LR comprised $0-25 \%$ of the MCs; however, it was $63 \%$ in the intestinal wall of $C$. carpio. In the liver, kidney and intestinal wall of the four fish species, the concentrations of MC-RR, MC-YR and MC-LR were, in decreasing order, MC-RR $>$ MC-LR $>$ MC-YR, except in C. carpio, in which the order was MC-LR $>$ MC-YR $>$ MC-RR. In the muscles of $H$. molitrix and $C$. carpio, the order was MC-RR > MCYR $>$ MC-LR, whereas in muscles of A. nobilis and C. auratus, it was MC-RR > MC-LR > MC-YR.

Of the four fish species, $C$. carpio had the highest mean concentration of MCs in the muscle $(31.7 \pm 12.1 \mathrm{ng} / \mathrm{g}, \mathrm{dm}$ ) (Table 2$)$, whereas $C$. auratus had the highest mean concentration of MCs in the liver $(45.4 \pm 44.5 \mathrm{ng} / \mathrm{g}, \mathrm{dm})$, kidney $(114 \pm 51.1 \mathrm{ng} / \mathrm{g}, \mathrm{dm})$, intestinal wall $\left(2.04 \times 10^{3} \pm 4.43 \times 10^{3} \mathrm{ng} / \mathrm{g}, \mathrm{dm}\right)$ and heart $(59.5 \pm 26.7 \mathrm{ng} / \mathrm{g}, \mathrm{dm})$ (Table 2). No significant differences in the MC concentrations in the same organs were observed between the phytoplanktivorous and omnivorous fishes. However, the mean MC concentrations in the muscle, kidney, intestinal wall and heart, but not liver, were significantly different among the four fishes, regardless of the feeding guild. For example, the mean MC concentration in the muscle was significantly higher in H. molitrix than A.nobilis $(p<0.01)$ or C. auratus $(p<0.05)$. The MC concentrations were significantly higher in $C$. carpio than $A$. nobilis $(p<0.01)$ or $C$. auratus $(p<0.01)$. C. carpio had higher mean concentrations of MCs in the kidneys than A. nobilis $(p<0.01)$, but lower mean concentrations than $C$. auratus $(p<0.01)$. However, $C$. auratus had higher mean concentrations of MCs in the kidneys than $H$. molitrix $(p<0.01)$. C. auratus had higher mean concentrations of MCs in the intestinal wall than $C$. carpio $(p<0.05)$. The mean MC concentration in 
hearts of different fish decreased in the following order: $C$. auratus $>H$. molitrix $>$ C. carpio $>$ A. nobilis $(p<0.05)$. The mean MC concentrations in the intestinal walls of the four fish species were significantly higher than in the other organs $(p<0.01)$. The mean MC concentrations in the kidneys of all species were higher than in the livers, which contradicts the results of previous studies.

\subsection{Spatial differences in the concentrations of MCs in fish}

Spatial differences in the MC concentrations in various organs of the fish species from the four sampled areas of the lake were compared (Fig. 2). The fish collected from LC had the highest mean concentration of MCs as follows: $33.7 \pm 11.3 \mathrm{ng} / \mathrm{g}$, dm in muscle, $84.8 \pm 68.8 \mathrm{ng} / \mathrm{g}$, $\mathrm{dm}$ in kidneys and $37.8 \pm 32.9 \mathrm{ng} / \mathrm{g}, \mathrm{dm}$ in hearts, whereas fish from MLB had the highest mean concentration of MCs in the livers (52.2 \pm $44.3 \mathrm{ng} / \mathrm{g}, \mathrm{dm})$ and intestinal walls $\left(2.80 \times 10^{3} \pm 4.77 \times 10^{3} \mathrm{ng} / \mathrm{g}, \mathrm{dm}\right)$.
C. carpio from LC had higher concentrations of MCs in the muscle of fish from the other locations (Fig. 2A), whereas $C$. auratus from MLB had the highest concentration of MCs in the liver and intestinal wall (Fig. 2B and D), and C. auratus from LC had the highest concentration of MCs in the kidney and heart (Fig. 2C and E). The MC concentrations in all organs except the kidney varied significantly among the locations $(p<0.05)$. The mean MC concentrations in all organs of the fish from MLB were significantly higher than those from LC, SC or WC $(p<0.01)$.

3.5. Relationships between the bioaccumulation of MCs and body length and mass of fishes

The correlations between the MC concentrations in the various organs and parameters including the body length and fish mass were determined (Table 3). The concentration of MCs in the muscle were not significantly correlated with the concentration in the liver, kidney,
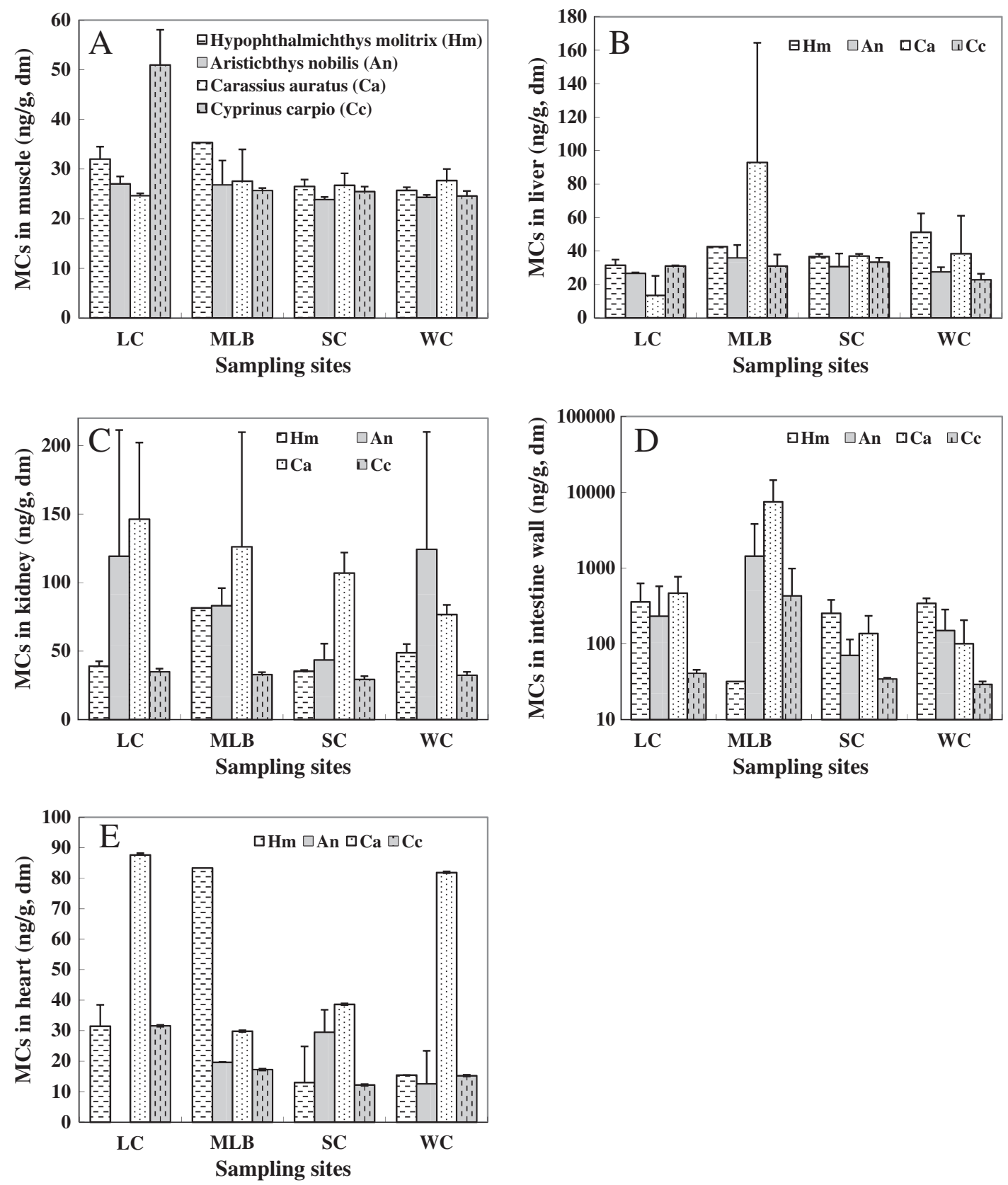

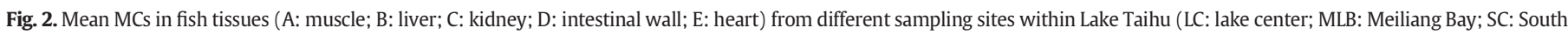
coast; WC: Westcoast; SC). 


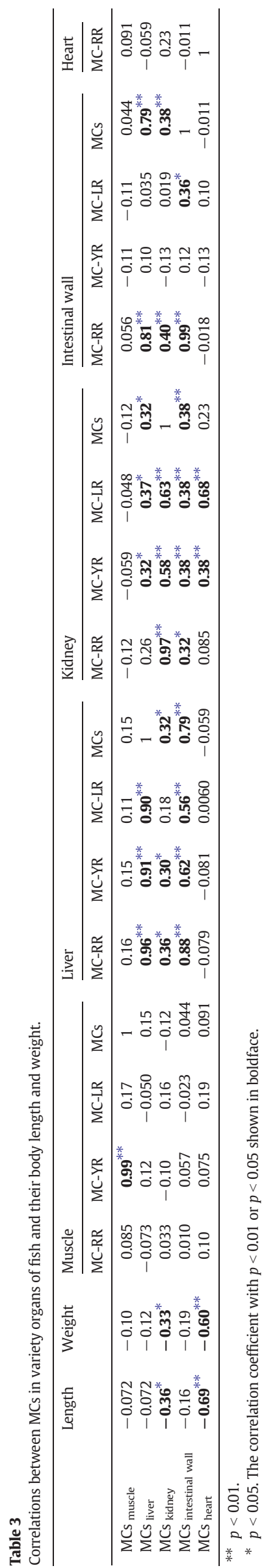

intestinal wall or heart. The MC concentrations in the liver were significantly and positively correlated with those in the intestinal wall $(p<0.01)$ and related to those in the kidney $(p<0.05)$. The MCs in kidney were significantly correlated with those in the intestinal wall $(p<0.01)$ and also related to the length and mass of the individual fish $(p<0.05)$. The concentration of MCs in the intestinal wall was significantly and positively correlated with those in the liver and the kidney $(p<0.01)$. The MC concentrations in the heart were significantly negatively correlated with the length and mass of the fish and also significantly correlated with concentrations of MC-RR and MC-LR in the kidney $(p<0.01)$. In addition, linear regression models fitted to the concentrations of MCs in the kidney and the heart suggested that small fish accumulate MCs to higher concentrations in these organs than larger fish (Fig. 3).

\subsection{Health risk}

Dietary exposure of humans to MCs was also calculated and compiled (Table 4). The World Health Organization (WHO) established a tolerable daily intake of $0.04 \mu \mathrm{g} / \mathrm{kg}$ body mass per day for MC-LR (Chorus and Bartram, 1999). The intra-peritoneal (i.p.) medium lethal doses $\left(\mathrm{LD}_{50}\right)$ in mice for MC-RR and -YR are approximately 5-fold and 2.5-fold higher than for MC-LR, respectively (Gupta et al., 2003), corresponding to 0.2 and $0.4 \mathrm{MC}$-LR equivalents, respectively. Assuming an average body mass of $60 \mathrm{~kg}$ for an adult in China and a daily consumption of fish muscle of $300 \mathrm{~g}$ (Zhang et al., 2009), the mean daily intakes of MCs from eating $H$. molitrix, A. nobilis, $C$. auratus and C. carpio would be $0.0475,0.0406,0.0435$ and $0.0525 \mu \mathrm{g}$ MC-LReq $/ \mathrm{kg}$ body mass, respectively. These average daily intakes (ADIs) are, respectively, 1.18-, 1.02-, 1.09-and 1.31-fold higher than the tolerable daily intake (TDI) proposed by the WHO. The average daily intake of MCs for all fish and the estimated daily intake of MCs in $55.6 \%$ of the muscle samples exceeded the provisional TDI proposed by the World Health Organization (WHO). The risks posed by consumption of the four species were decreased in the order: C. carpio $>H$. molitrix $>C$. auratus $>A$. nobilis. Generally, the risks due to the consumption of omnivorous fish were slightly higher than those due to the consumption of phytoplanktivorous fish. Because C. carpio had the highest mean concentration of MCs in the muscle, consumption of the muscle of this species should be minimised. Compared to previous studies, the risk posed by the consumption of MCs in the muscle of fish from Lake Chaohu, Anhui province (Xie et al., 2005) was much higher than for fish from Lake Taihu, and omnivorous fish posed the highest risk (Table 4).

\section{Discussion}

In the present study, the ratios of MC-RR/MCs, MC-YR/MCs and MCLR/MCs in the various organs of four fish species were different. This may be explained by their different feeding guilds. The diet of phytoplanktivorous fishes in Lake Taihu comprises 90\% Microcystis sp. (Liu, 2008). The diet of the omnivorous species C. auratus comprises 85\% Microcystis sp., whereas the other omnivorous fish species C. carpio does not consume Microcystis sp. (Table 1) (Liu, 2008). The mean concentrations of MCs in the different organs of the two phytoplanktivorous fishes, $H$. molitrix and A. nobilis, were not significantly different, and the order of organ-specific accumulation of MCs was the same for both species. However, significant variations were found between the MC concentrations in the organs of the omnivorous species, C. auratus and C. carpio.

The concentrations of MCs in the tissues and organs of phytoplanktivorous fishes were relatively low and lower than previously reported for omnivorous fishes (Xie et al., 2005). However, other authors found MC concentrations in phytoplanktivorous fishes (Zhang et al., 2009) higher than those reported by Xie et al. (2005). No significant difference was observed for the MC concentrations between phytoplanktivorous and omnivorous fishes $(p>0.05)$ in the present 

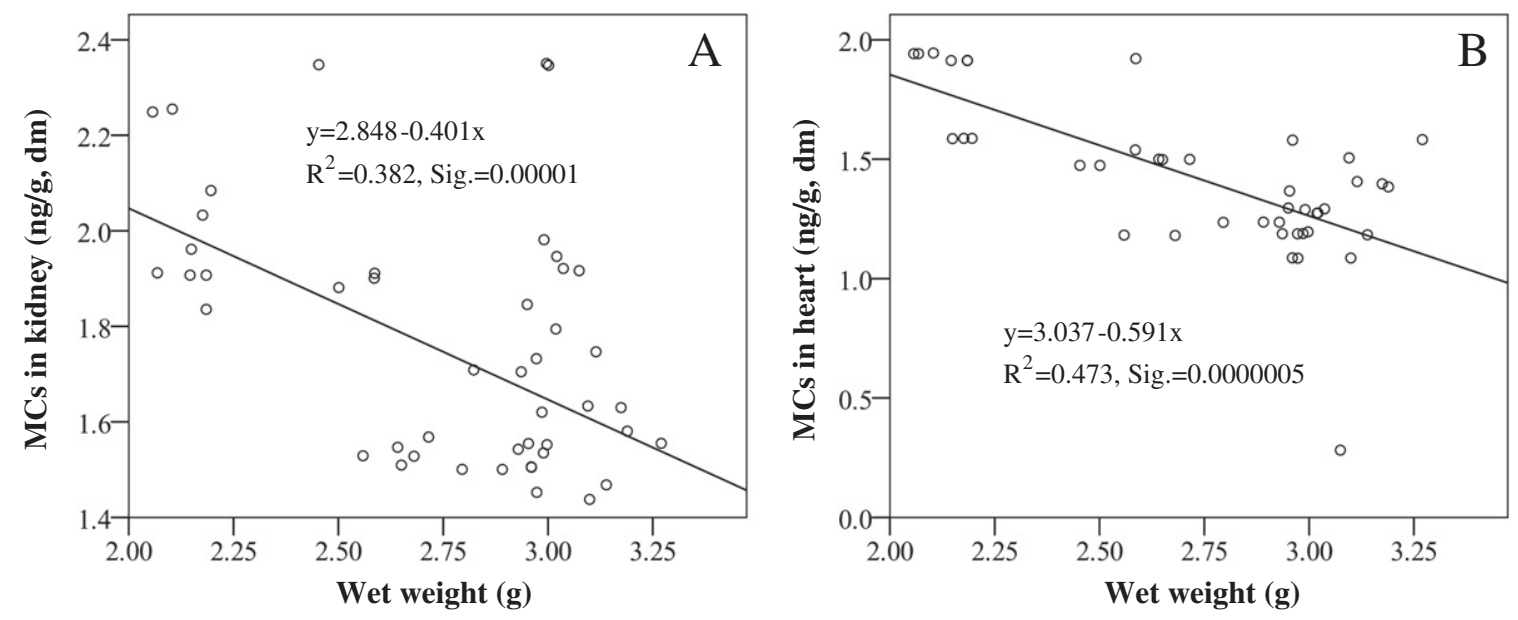

Fig. 3. MC concentrations in kidney (A) and heart (B) of fishes as a function of wet weight. Linear models were fit to the data and the equations are presented.

study. These results suggest that the MC concentration in fishes is not only a function of the species feeding guild but also depends on the duration of exposure to the toxin and the rates of accumulation relative to depuration (Ibelings and Chorus, 2007) together with the different metabolic rates of the fish species. However, the accumulation of MCs has species-specific pathological effects. Phytoplanktivorous fishes may be more tolerant of the effects of MCs than other species (Xie et al., 2004). Previous investigations of the fish species in this study have shown more serious damage to the livers of the omnivorous species than the phytoplanktivorous species as a result of exposure to cyanobacterial blooms. Morphological alterations of the nuclei and the production of lipid droplets were observed (Qiu et al., 2007a). These authors excluded oxygen deficiency as a possible cause of liver damage and demonstrated that the exposure to MCs was responsible for the pathological changes observed in the liver. Previous controlled trials have demonstrated that MCs can induce pathological changes, disrupt the biochemical index, affect the nutritional status of fish and cause normocyte anaemia in some animals. One study showed that MCs in C. carpio (common carp) adversely affected epithelial cells, taste buds and gill filaments (Jiang et al., 2011). Toxicity tests in adult Danio rerio (zebrafish) under laboratory conditions showed that trace amounts of MCs were likely to have deleterious effects on aquatic organisms and trigger a variety of biochemical responses depending on their specific toxicity (Pavagadhi et al., 2012). Blooms of cyanobacteria may also affect the nutritional status and health of the splittail (Pogonichthys macrolepidotus) (Acuna et al., 2012).

The concentrations of MCs in the intestinal wall were significantly higher than in other organs. This result is consistent with previous studies (Chen et al., 2006; Zhang et al., 2009), which indicate that accumulation in the intestinal wall can inhibit further transport of MCs into internal organs. The MC concentrations in the livers of the four fish species studied here were all relatively low, which contradicts the results of previous studies (Kankaanpää et al., 2005; Li et al., 2004; Malbrouck et al., 2003; Xie et al., 2005). The liver is an important detoxification organ, and bile plays an important role in the elimination and recirculation of excess MCs from the fish liver (Tencalla and Dietrich, 1997). This is the first study to examine the accumulation of MCs in the heart tissue of wild fish. The accumulation of MCs may have adverse effects on heart

Table 4

Microcystin consumption in human diet.

\begin{tabular}{|c|c|c|c|c|c|c|}
\hline Species $^{a}$ & Sampling site & $\begin{array}{l}\text { Daily intake } \\
(\mathrm{g} / \mathrm{d})\end{array}$ & $\begin{array}{l}\text { MC in muscle } \\
\text { (MC-LReq, ng/g) }\end{array}$ & $\begin{array}{l}\text { Daily intakes for a } 60 \mathrm{~kg} \text { person } \\
\text { (MC-LR eq/kg body weight) }\end{array}$ & $\begin{array}{l}\times \text { Lifetime } \text { TDI }^{\mathrm{b}} \\
(0.04 \mu \mathrm{g} / \mathrm{kg} \text { body weight/d })\end{array}$ & References \\
\hline Planktivorous & & & $21.0 \pm 25.5$ & $0.0502 \pm 0.0347$ & $1.25 \pm 0.87$ & \\
\hline $\mathrm{Hm}$ & Lake Taihu & 300 & 9.50 & 0.0475 & 1.19 & In present study \\
\hline $\mathrm{Hm}$ & Lake Taihu & 100 & 16.1 & 0.0267 & 0.67 & Chen et al. (2006) \\
\hline $\mathrm{Hm}$ & Lake Taihu & 300 & 5.20 & 0.026 & 0.65 & Zhang et al. (2009) \\
\hline $\mathrm{Hm}$ & Lake Chaohu & 100 & 66.0 & 0.11 & 2.75 & Xie et al. (2005) \\
\hline An & Lake Taihu & 300 & 8.13 & 0.0406 & 1.02 & In present study \\
\hline Omnivorous & & & $136 \pm 210$ & $0.242 \pm 0.343$ & $6.05 \pm 8.57$ & \\
\hline $\mathrm{Ca}$ & Lake Taihu & 300 & 8.70 & 0.0435 & 1.09 & In present study \\
\hline $\mathrm{Ca}$ & Lake Taihu & 300 & $34^{c}$ & & $\mathrm{~N}^{\mathrm{d}}$ & Zhang et al. (2009) \\
\hline $\mathrm{Ca}$ & Lake Chaohu & 100 & 497 & 0.828 & 20.7 & Xie et al. (2005) \\
\hline $\mathrm{Cc}$ & Lake Taihu & 300 & 10.5 & 0.0525 & 1.31 & In present study \\
\hline $\mathrm{Cc}$ & Lake Taihu & 300 & $67^{c}$ & & $\mathrm{E}^{\mathrm{d}}$ & Zhang et al. (2009) \\
\hline $\mathrm{Cc}$ & Lake Chaohu & 100 & 26 & 0.0433 & 1.08 & Xie et al. (2005) \\
\hline Carnivorous & & & $62.0 \pm 74.9$ & $0.105 \pm 0.123$ & $2.62 \pm 3.07$ & \\
\hline $\mathrm{Ci}$ & Lake Taihu & 300 & 1.6 & 0.008 & 0.2 & Zhang et al. (2009) \\
\hline $\mathrm{Ci}$ & Lake Chaohu & 100 & 109 & 0.182 & 4.5 & Xie et al. (2005) \\
\hline $\mathrm{Nt}$ & Lake Taihu & 300 & 0.8 & 0.004 & 0.1 & Zhang et al. (2009) \\
\hline $\mathrm{Ce}$ & Lake Taihu & 300 & 0.6 & 0.003 & 0.075 & Zhang et al. (2009) \\
\hline $\mathrm{Ce}$ & Lake Chaohu & 100 & 182 & 0.303 & 7.58 & Xie et al. (2005) \\
\hline Pf & Lake Chaohu & 100 & 78 & 0.13 & 3.25 & Xie et al. (2005) \\
\hline
\end{tabular}

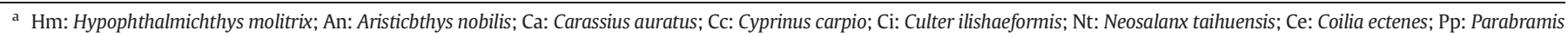
pekinensis; Pf: Pseudobagrus fulvidraco.

b TDI: tolerance daily intake.

c MCs.

d N: not exceed the TDI; E:exceed the TDI. 
function, such as reduced heart rate, pericardial oedema and tubular heart and bradycardia.

There were significant differences in the concentrations of MCs in the muscle, liver, intestinal wall and heart of fish from different locations, suggesting that environmental factors influence the accumulation of MCs in fish organs. However, highly mobile animals such as fish may be exposed to varying levels of contaminants throughout their life cycle; therefore, it is challenging to identify the primary environmental factors that contribute to the variability in MC accumulation. According to the results of a previous study (Xie et al., 2004), during a period of 20 days without exposure to cyanobacteria, the MC concentrations in the liver and muscle of $H$. molitrix decreased by between two and eightfold. In the present study, fish from MLB had the highest mean concentrations of MCs in the livers and intestinal walls. This may be because of the uneven distribution of algal populations across Lake Taihu or to variability in the digestion of algae or debris in the intestine. The population density of the cyanobacteria at MLB $\left(3.24 \times 10^{7}\right.$ cell/L) was higher than that at other locations, such as WC, where it was $3.05 \times 10^{7}$ algae cell $/ \mathrm{L}$, SC $\left(1.85 \times 10^{7}\right.$ algae cell/L) and LC $\left(1.77 \times 10^{7}\right.$ algae cell/L) (Authority, 2011). The importance of the liver as an elimination and recirculation organ for MCs (Tencalla and Dietrich, 1997) suggests that liver MC accumulation is related to algal cell density in the water column. Fish from LC had the highest mean concentrations of MCs in the muscle, kidneys and hearts. It is likely that routes other than the gastrointestinal tract are important for the uptake of MCs by fish, such as $C$. ilishaeformis and $C$. carpio (Xie et al., 2005). This may also explain why $C$. carpio from LC had the highest concentrations of MCs in the muscle, despite having the lowest concentration of MCs in the intestinal wall of all of the species from LC (Fig. 2D). Similarly, the highest concentrations of MC-RR in the muscle were found in C. ilishaeformis, despite the absence of MCs in their guts (Xie et al., 2005). Additional studies are necessary to better elucidate the importance of different possible uptake pathways for MCs into fish tissue.

Smaller fish accumulated higher concentrations of MCs in the kidney and the heart than larger fish. This may be because biotransformation and excretion are less well-developed in smaller fish. The significant relationships among MCs (MC-RR, MC-YR and MC-LR) in the liver, kidney and intestinal wall show that the primary uptake of MCs for the four fish species is the gastrointestinal tract and also indicate that organs, such as the liver and the kidney, may have interrelated functions in the MC accumulation and depuration processes, which require further research. There were no significant relationships between the MC-YR in the intestinal wall and MCs in the liver and the kidney, indicating that MC-YR may have different uptake routes than MC-LR and MC-RR. Furthermore, the MC-YR concentrations in the intestinal wall were not significantly higher than in the liver and the kidney, and the MC-YR in the C. auratus kidney was higher than in the intestinal wall (Table 2). The main uptake route of MC-YR for $C$. auratus appeared to be by direct uptake of dissolved MCs via the gills and not via the gastrointestinal tract (Zhang et al., 2009).

In the present study, the mean concentrations of MCs in the kidney, liver and muscle of the silver carp were 45.1, 40.0 and $29.1 \mathrm{ng} / \mathrm{g}$, dm, respectively. In another study of Lake Taihu, the average concentrations of MCs in the liver and muscle of silver carp were 48 and $26 \mathrm{ng} / \mathrm{g}$, dm, respectively (Zhang et al., 2009). However, at the same study site, in the presence of dense cyanobacteria blooms, the mean concentrations of MCs in the kidney, liver and muscle of the silver carp were 782, 957 and $197 \mathrm{ng} / \mathrm{g}$, dm, respectively (Chen et al., 2006). There was relatively large variability in the organ concentrations of MCs among the fish with different life histories or from different feeding guilds, whether in the presence or absence of cyanobacteria blooms. This may be because of different degrees of digestion of MCs or the heterogeneity in food sources (Chen et al., 2006). Variations in the concentrations of MCs were higher than for fish from other lakes. For example, in Lake Chaohu, in the presence of dense cyanobacterial blooms, the mean concentration of MCs in the kidney, liver and muscle of $H$. molitrix were as high as
$5.81 \times 10^{3}, 7.77 \times 10^{3}$ and $1.81 \times 10^{3} \mathrm{ng} / \mathrm{g}, \mathrm{dm}$, respectively (Xie et al., 2005). Many lakes and reservoirs in China, such as Lake Chaohu and the Yanghe Reservoir, Hubei province (Li et al., 2010), Dianchi Lake, Yunnan province (Zhang et al., 2012) suffer from cyanobacteria blooms and consequently exhibit high concentrations of MCs. Based on the available evidence, fish in these waters would also be expected to have significantly high concentrations of MCs.

\section{Conclusions}

By quantifying the MC concentrations in different fish species from four different areas of Lake Taihu, the MC concentrations in the organs of the different fish species and the spatial variation were determined. The accumulation of MCs in fish varies among species. However, in this study, no significant difference in the MC concentrations between phytoplanktivorous and omnivorous fish was observed. The MC concentrations in the intestinal wall were significantly higher than in the other organs. As a result of their feeding ecology, C. carpio accumulated higher concentrations of MCs in the muscle than the other fish species, and $C$. auratus accumulated higher concentrations of MCs in their internal organs. The MC concentrations of fish from MLB were significantly higher than in fishes from the other three areas of the lake $(p<0.01)$. Biotic and abiotic factors influencing the accumulation of MCs in fish were also evaluated. The consumption of algal cells was the main factor to influence the accumulation of MCs by fish. Smaller fish accumulated more MCs in their kidneys and hearts. The ADI values based on the consumption of these four fish all exceeded the provisional tolerable daily intake (TDI) proposed by the WHO. The estimated daily intakes of MCs in $55.6 \%$ of the muscle samples were higher than the provisional TDI set by the WHO.

\section{Acknowledgements}

This research was supported by the National Natural Science Foundation of China under Grant No. 2008CB418104, the National Natural Science Foundation of China under Grant No. 41271502 and Strategic Priority Research Program of the Chinese Academy of Sciences, Grant No. XDB03030504. Prof. Giesy was supported by the programme of 2012 "High Level Foreign Experts" (\#GDW20123200120) funded by the State Administration of Foreign Experts Affairs, the P.R. China to Nanjing University and the Einstein Professor Program of the Chinese Academy of Sciences. He was also supported by the Canada Research Chair programme, a Visiting Distinguished Professorship in the Department of Biology and Chemistry and State Key Laboratory in Marine Pollution, City University of Hong Kong. Thanks were given to Dr. Stephen Lofts in the UK Natural Environment Research Council for his efforts to improve English grammar of this manuscript.

\section{References}

Acuna S, Deng DF, Lehman P, Teh S. Sublethal dietary effects of microcystis on Sacramento splittail, Pogonichthys macrolepidotus. Aquat Toxicol 2012;110:1-8.

Ame MV, Galanti LN, Menone ML, Gerpe MS, Moreno VJ, Wunderlin DA. Microcystin-LR, -RR, -YR and -LA in water samples and fishes from a shallow lake in Argentina. Harmful Algae 2010;9:66-73.

Authority TB. Taihu Lake health status report; 2011. p. 14-5.

Carmichael WW. Cyanobacterial secondary metabolites - the cyanotoxins. J Appl Bacteriol 1992;72:445-59.

Carmichael WW. The toxins of cyanobacteria. Sci Am 1994;270:78-86.

Cazenave J, Wunderlin DA, Bistoni MDLÁ, Amé MV , Krause E, Pflugmacher S, et al. Uptake, tissue distribution and accumulation of microcystin-RR in Corydoras paleatus, Jenynsia multidentata and Odontesthes bonariensis: a field and laboratory study. Aquat Toxicol 2005:75:178-90.

Chen Q, Mynett AE. Integration of data mining techniques and heuristic knowledge in fuzzy logic modelling of eutrophication in Taihu Lake. Ecol Model 2003;162:55-67.

Chen J, Xie P. Seasonal dynamics of the hepatotoxic microcystins in various organs of four freshwater bivalves from the large eutrophic Lake Taihu of subtropical China and the risk to human consumption. Environ Toxicol 2005a;20:572-84.

Chen J, Xie P. Tissue distributions and seasonal dynamics of the hepatotoxic microcystinsLR and -RR in two freshwater shrimps, Palaemon modestus and Macrobrachium 
nipponensis, from a large shallow, eutrophic lake of the subtropical China. Toxicon 2005b;45:615-25.

Chen YF, Zhu SQ. Change of fish fauna and long-term dynamics of the harvest of aquatic product in a large shallow lake (Lake Taihu, China). J Fish Aquat Sci 2008;3:72-6.

Chen J, Xie P, Zhang DW, Ke ZX, Yang H. In situ studies on the bioaccumulation of microcystins in the phytoplanktivorous silver carp (Hypophthalmichthys molitrix) stocked in Lake Taihu with dense toxic Microcystis blooms. Aquaculture 2006;261: 1026-38.

Chen J, Xie P, Li L, Xu J. First identification of the hepatotoxic microcystins in the serum of a chronically exposed human population together with indication of hepatocellular damage. Toxicol Sci 2009;108:81-9.

Chorus I, Bartram J. Toxic cyanobacteria in water: a guide to their public health consequences, monitoring and management. London and New York: E \& FN Spon; 1999.

Dawson RM. The toxicology of microcystins. Toxicon 1998;36:953-62.

Gkelis S, Lanaras T, Sivonen K. The presence of microcystins and other cyanobacterial bioactive peptides in aquatic fauna collected from Greek freshwaters. Aquat Toxicol 2006;78:32-41.

Gupta N, Pant SC, Vijayaraghavan R, Rao PVL. Comparative toxicity evaluation of cyanobacterial cyclic peptide toxin microcystin variants (LR, RR, YR) in mice. Toxicology 2003;188:285-96.

Ibelings BW, Chorus I. Accumulation of cyanobacterial toxins in freshwater "seafood" and its consequences for public health: a review. Environ Pollut 2007:150:177-92.

Jiang JL, Gu XY, Song R, Zhang Q Geng JJ, Wang XR, et al. Time-dependent oxidative stress and histopathological changes in Cyprinus carpio L. exposed to microcystin-LR. Ecotoxicology 2011;20:1000-9.

Jin X, Hu X. A comprehensive plan for treating the major polluted regions of Lake Taihu, China. Lakes Reserv Res Manag 2003;8:217-30.

Kaebernick M, Neilan BA. Ecological and molecular investigations of cyanotoxin production. FEMS Microbiol Ecol 2001:35:1-9.

Kankaanpää HT, Holliday J, Schröder H, Goddard TJ, von Fister R, Carmichael WW. Cyanobacteria and prawn farming in northern New South Wales, Australia-a case study on cyanobacteria diversity and hepatotoxin bioaccumulation. Toxicol Appl Pharmacol 2005;203:243-56.

Kotak BG, Semalulu S, Fritz DL, Prepas EE, Hrudey SE, Coppock RW. Hepatic and renal pathology of intraperitoneally administered microcystin-LR in rainbow trout (Oncorhynchus mykiss). Toxicon 1996:34:517-25.

Li JZ. Agilent 1260 UHPLC/6460QQQ used for the detection of microcystins. Environ Chem 2011;30:731-3.

Li XY, Chung IK, Kim JI, Lee JA. Subchronic oral toxicity of microcystin in common carp (Cyprinus carpio L.) exposed to Microcystis under laboratory conditions. Toxicon 2004; $44: 821-7$.

Li L, Xie P, Chen J. In vivo studies on toxin accumulation in liver and ultrastructural changes of hepatocytes of the phytoplanktivorous bighead carp i.p.-injected with extracted microcystins. Toxicon 2005;46:533-45.

Li ZL, Yu JW, Yang M, Zhang J, Burch MD, Han W. Cyanobacterial population and harmful metabolites dynamics during a bloom in Yanghe Reservoir, North China. Harmful Algae 2010;9:481-8.

Liu ES. A study on diet composition of dominant fishes in Lake Taihu (in Chinese). J Fish China 2008;32:395-401.

Magalhàes VF, Soares RM, Azvedo S. Microcystin contamination in fish from Jacarepaguá Lagoon (Rio de Janeiro, Brazil): ecological implication and human health risk. Toxicon 2001;39:1077-85.

Magalhaes VF, Soares RM, Azevedo SM. Microcystin contamination in fish from the Jacarepagua Lagoon (Rio de Janeiro, Brazil): ecological implication and human health risk. Toxicon 2001;39:1077-85.

Magalhães VF, Marinho MM, Domingos P, Oliveira AC, Costa SM, Azevedo LO, et al. Microcystins (cyanobacteria hepatotoxins) bioaccumulation in fish and crustaceans from Sepetiba Bay (Brasil, RJ). Toxicon 2003;42:289-95.

Malbrouck C, Trausch G, Devos P, Kestemont P. Hepatic accumulation and effects of microcystin-LR on juvenile goldfish Carassius auratus L. Comp Biochem Physiol C Toxicol Pharmacol 2003;135:39-48.

McElhiney J, Lawton LA. Detection of the cyanobacterial hepatotoxins microcystins. Toxicol Appl Pharmacol 2005;203:219-30.
Melwani AR, Bezalel SN, Hunt JA, Grenier JL, Ichikawa G, Heim W, et al. Spatial trends and impairment assessment of mercury in sport fish in the Sacramento-San Joaquin Delta watershed. Environ Pollut 2009;157:3137-49.

Mohamed ZA, Hussein AA. Depuration of microcystins in tilapia fish exposed to natura populations of toxic cyanobacteria: a laboratory study. Ecotoxicol Environ Saf 2006: 63:424-9.

Mohamed ZA, Carmichael WW, Hussein AA. Estimation of microcystins in the freshwater fish Oreochromis niloticus in an Egyptian fish farm containing a Microcystis bloom. Environ Toxicol 2003;18:137-41.

Nishiwakimatsushima R, Ohta T, Nishiwaki S, Suganuma M, Kohyama K, Ishikawa T, et al. Liver-tumor promotion by the cyanobacterial cyclic peptide toxin microcystin-LR. J Cancer Res Clin Oncol 1992;118:420-4.

Otten TG, Xu H, Qin B, Zhu G, Paerl HW. Spatiotemporal patterns and ecophysiology of toxigenic microcystis blooms in Lake Taihu, China: implications for water quality management. Environ Sci Technol 2012;46:3480-8.

Pan G, Chen J, Anderson DM. Modified local sands for the mitigation of harmful algal blooms. Harmful Algae 2011;10:381-7.

Pavagadhi S, Gong ZY, Hande MP, Dionysiou DD, de la Cruz AA, Balasubramanian R. Biochemical response of diverse organs in adult Danio rerio (zebrafish) exposed to sublethal concentrations of microcystin-LR and microcystin-RR: a balneation study Aquat Toxicol 2012;109:1-10.

Peng LA, Liu YM, Chen W, Liu LM, Kent M, Song LR. Health risks associated with consumption of microcystin-contaminated fish and shellfish in three Chinese lakes: significance for freshwater aquacultures. Ecotoxicol Environ Saf 2010;73:1804-11.

$\mathrm{Pu}$ PM, Hu WP, Yan JS, Wang GX, Hu CH. A physico-ecological engineering experiment for water treatment in a hypertrophic lake in China. Ecol Eng 1998:10:179-90.

Qiu T, Xie P, Ke Z, Li L, Guo L. In situ studies on physiological and biochemical responses of four fishes with different trophic levels to toxic cyanobacterial blooms in a large Chinese lake. Toxicon 2007a:50:365-76.

Qiu T, Xie P, Ke ZX, Li L, Guo LG. In situ studies on physiological and biochemical responses of four fishes with different trophic levels to toxic cyanobacterial blooms in a large Chinese lake. Toxicon 2007b;50:365-76.

Sun X, Tao M, Qin B, Qi M, Niu Y, Zhang J, et al. Large-scale field evidence on the enhancement of small-sized cladocerans by Microcystis blooms in Lake Taihu, China. J Plankton Res 2012;34:853-63.

Tencalla F, Dietrich D. Biochemical characterization of microcystin toxicity in rainbow trout (Oncorhynchus mykiss). Toxicon 1997;35:583-95.

Vasconcelos VM, Pereira E. Cyanobacteria diversity and toxicity in a wastewater treatment plant (Portugal). Water Res 2001;35:1354-7.

Williams DE, Dawe SC, Kent ML, Andersen RJ, Craig M, Holmes CFB. Bioaccumulation and clearance of microcystins from salt water, mussels, Mytilus edulis, and in vivo evidence for covalently bound microcystins in mussel tissues. Toxicon 1997;35: $1617-25$.

Xie P, Liu J. Practical success of biomanipulation using filter-feeding fish to contro cyanobacteria blooms: a synthesis of decades of research and application in a subtropical hypereutrophic lake. ScientificWorldJournal 2001;1:337-56.

Xie LQ, Xie P, Ozawa K, Honma T, Yokoyama A, Park HD. Dynamics of microcystins-LR and -RR in the phytoplanktivorous silver carp in a sub-chronic toxicity experiment. Environ Pollut 2004;127:431-9.

Xie LQ, Xie P, Guo LG, Li L, Miyabara Y, Park HD. Organ distribution and bioaccumulation of microcystins in freshwater fish at different trophic levels from the eutrophic Lake Chaohu, China. Environ Toxicol 2005;20:293-300.

Zhang DW, Xie P, Liu YQ, Qiu T. Transfer, distribution and bioaccumulation of microcystins in the aquatic food web in Lake Taihu, China, with potential risks to human health. Sci Total Environ 2009;407:2191-9.

Zhang JQ Wang Z, Song ZY, Xie ZC, Li L, Song LR. Bioaccumulation of microcystins in two freshwater gastropods from a cyanobacteria-bloom plateau lake, Lake Dianchi. Environ Pollut 2012;164:227-34.

Zurawell RW, Kotak BG, Prepas EE. Influence of lake trophic status on the occurrence of microcystin-LR in the tissue of pulmonate snails. Freshw Biol 1999;42:707-18. 